\title{
Effectiveness of Video Assisted Teaching Programme on Knowledge Regarding Prevention of Shaken Baby Syndrome among Antenatal Women at Selected Hospitals of Banglore, India
}

\begin{abstract}
Punita Yadav ${ }^{*}$, Menaga $\mathbf{P}^{2}$, Sunil Kumar Bhinawar ${ }^{3}$
${ }^{1}$ Department of Nursing, Krishna Medical Technical Research Center, Purbanchal University, Nepal, 2Department of Obstetrics and Gynaecological Nursing, Vydehi Institute of Nursing Sciences \& Research Centre, Bangalore, India, ${ }^{3}$ Department of Pediatrics, Janaki Medical College, Tribhuvan University, Janakpur, Nepal
\end{abstract}

\section{ARTICLE INFO}

Article history: Received: 17 March 2021 Revised: 27 April 2021 Accepted: 11 June 2021

*Correspondence:

Mrs. Punita Yadav Lecturer

Obstetrics and Gynaecological Nursing, Krishna Medical Technical Research Center. Purbanchal University, Nepal

Email: ypunitak@gmail.com

Citation:

Yadav P, Menaga P, Bhinawar SK. Effectiveness of Video Assisted Teaching Programme on Knowledge Regarding Prevention of Shaken Baby Syndrome among Antenatal Women at Selected Hospitals of Bangalore, India. MedS. J. Med. Sci. 2021; 1(1):83-88.

\begin{abstract}
ABSTARCT
INTRODUCTION: The objective of the study was to evaluate the effectiveness of video assisted teaching on knowledge regarding prevention of shaken baby syndrome among antenatal women and also the association between knowledge with their selected socio-demographical variables. MATERIALS AND METHODS: A one group pre-test and post-test design was adopted. Structured knowledge questionnaire was prepared. The data were collected from 60 women who attend the OPD for antenatal regular checkup using non probability purposive sampling techniques. The reliability of tools was established (0.724).Pilot study was conducted. The data was analyzed and interpreted using descriptive and inferential statistics. RESULTS: The findings revealed that the overall mean pre-test Knowledge score was 11.06 and the overall post-test knowledge score was 19.98 respectively. The mean post-test knowledge score of antenatal women who were exposed to video assisted teaching were significantly higher, than the mean pretest knowledge scores. There was suggestive significance between the knowledge scores and demographic variables. The findings suggest that the video assisted teaching program is an effective teaching strategy to enhance the knowledge of antenatal women, regarding prevention of shaken baby syndrome. CONCLUSIONS: The post-test knowledge score was higher than pretest knowledge score regarding prevention of Shaken Baby Syndrome among antenatal women.The study concluded that, the video assisted teaching Program was an effective teaching strategy, to enhance knowledge of antenatal women regarding prevention of shaken baby syndrome.
\end{abstract}

Keywords: Antenatal women, effectiveness, knowledge, shaken baby syndrome, video assisted teaching

\section{INTRODUCTION}

Shaken baby syndrome (SBS) is a collective term for internal head injuries of a baby or young child, sustained from being violently shaken. It was first identified in the 1970s by Caffey as whiplash injury [1]. SBS is also known as abusive head trauma, shaken brain trauma, pediatric traumatic brain injury, whiplash shaken baby syndrome and shaken impact syndrome [2]. The brain damage can also be as a result of an accident. The force and length of the force necessary to cause shaken baby syndrome is debatable. But, over 20 seconds of continuous vigorous shaking of the baby for various causes like shaking baby in joy or while consoling the cry of baby itself may lead to this syndrome [3]. A child or baby who has been shaken and has pressure on the brain and may have symptoms like: extreme irritability, vomiting, poor appetite or feeding problems, breathing difficulties, convulsions, lethargy, pale or blue-colored skin, bruising (grab marks on the arms or chest), forehead that appears larger than usual, or a 
soft spot that seems to be bulging, inability to lift his or her head, tremors, unconsciousness and coma. The injuries seen in SBS may include subdural hematomas, sub-arachnoid hemorrhage, retinal hemorrhages, ribs fractures, long bone fracture bruises, laceration or other fracture due to impact. Shaking can cause brain injury, cerebral palsy, blindness, hearing loss, learning and behavior problems, seizures, paralysis and death [4]. In surveys carried out in the USA, $50 \%$ to $75 \%$ of teenagers and young adults stated they did not know that shaking was dangerous and between $2.6 \%$ and $4.4 \%$ of the parents of children under 2 years of age reported they had shaken their child at least once. The equivalent figure for parents in Indian city slums was $42 \%$ [5]. Statistics indicate that two-thirds to

\section{MATERIALS AND METHODS}

\section{Study design and setting}

This pilot study was conducted in the Department of Obstetrics and Gynaecological Nursing, Vydehi Institute of Nursing Sciences \& Research Centre, Bangalore from in 2017 AD. Non-probability purposive sampling technique was used.

\section{Participants and study procedures}

An average of 3-5 antenatal women were selected each day. Sixty antenatal women were selected from Obstetrics and Gynaecology OPD. The purpose of the study was explained and the subject's willingness to participate in the study was ascertained. The investigator administered questionnaire for pretest. Each subject took 5-7 minutes. After the completion of the pretest through video assisted teaching program, a sequential presentation of information regarding prevention of SBS such as definition, incidence, risk factors, signs and symptoms, management, complication, prognosis and preventive measures with the help of video was organized and it was conducted on same day for 20-25 minutes. Post test was conducted on next visit in the same manner as pretest was conducted. Antenatal woman attending regular antenatal visit at OPD who were primi and multi gravida were included.

Also, antenatal woman who were in 32 -38 weeks of three-fourths of the people found guilty of shaking babies are male. It is not only males who shake babies, mothers, caregivers and siblings have also been found to have shaken babies. SBS can happen among families of any ethnicity, any income range and with any type of family composition [6]. The incidence of SBS peaks between 2.5 and 4 months, and it is estimated that the first episode likely occurs around 6 weeks, the average age at which crying peaks. Therefore, the objective of this study was to evaluate the effectiveness of video assisted teaching on knowledge regarding prevention of SBS among antenatal women and the association between knowledge with their selected socio-demographical variables.

gestational period were included. Antenatal woman not willing to participate and who were sick during the time of data collection were excluded. Structured knowledge based questionnaire was chosen to assess the knowledge level of antenatal women with the help of literature reviews, expert's suggestions and opinions. The validity of the tool was checked by four experts and as per their suggestion, required modification was made.

Demographic variables of antenatal women such as age, religion, education, occupation, place of residence, family monthly income, gravida, types of family, information about SBS was included. The pretest was conducted in Vydehi hospital, Whitefield, Bangalore. The reliability was established by test and retest method using Karl Pearson"s correlation coefficient method.

Ethical approval was obtained from Vydehi Institute of Nursing Sciences and Research Centre, Bangalore. A written informed consent was also taken individually from all the subjects who participated in this study. The subjects were informed that their participation was voluntary and had the freedom to dropout from the study when they liked to do so. The subjects were assured for anonymity and confidentiality of the information provided by them. 


\section{Statistical consideration}

The data was analyzed in terms of frequency, percentage, mean, standard deviation and was presented in the form of tables and diagrams.

\section{RESULTS}

Distribution of socio-demographic variables of antenatal women

Out of 60 respondents, $26(43.3 \%)$ of the subjects were in the age group of 21-25 years, 18 (30\%) subjects were in the age of 26-30 group years, and $16(26.7 \%)$ subjects were in the age group of $31-35$ years. Majority of women were housewives, resided in urban area with family income between Rs. 5,000 to 10,000 . Most of the subjects $45(75 \%)$ were Hindu, $11(18.3 \%)$ were Christian and $4(6.7 \%)$ were Muslim. Regarding educational qualification, majority of antenatal women $20(33.3 \%)$ received PUC level qualification, $16(26.7 \%)$ had primary qualification, 8 (13.3\%) had secondary level qualification, $10(16.7 \%)$ and $6(10 \%)$ had graduate and postgraduate qualification (Table 1).

Distribution of antenatal women according to the gravida showed that $35(58.3 \%)$ subjects were primigravida and $25(41.7 \%)$ were multigravida (Figure 1). Figure 2 shows, the distribution of antenatal women according to the types of family where $34(56.67 \%)$ subjects belonged to nuclear family, $24(40 \%)$ belonged to joint family and 2 (3.33\%) belonged to extended family.

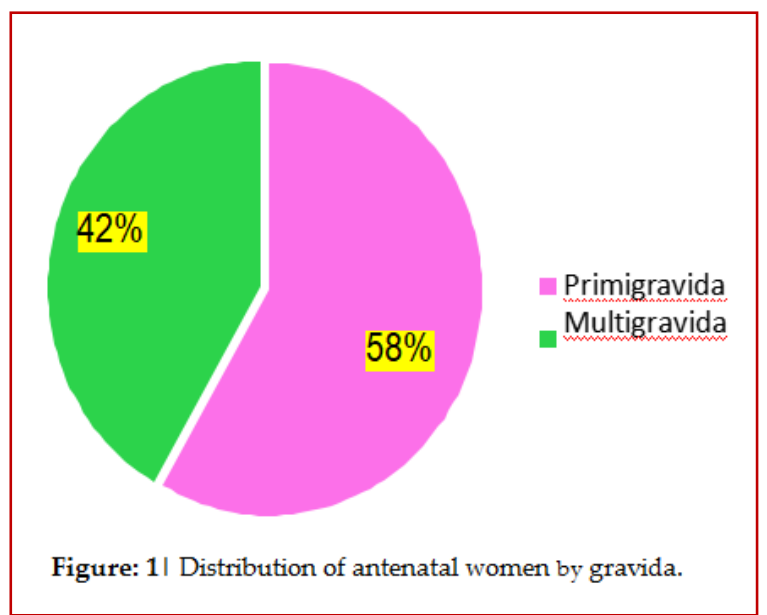

Significant difference between mean of pretest and posttest of knowledge was determined by using ' $\mathrm{t}^{\prime}$ test and chi-square test. All the analysis was carried out through SPSS version 21 software.

\begin{tabular}{|c|c|c|}
\hline Characteristics & $\mathbf{N}$ & $\%$ \\
\hline \multicolumn{3}{|l|}{ Age in years } \\
\hline $21-25$ & 26 & 43.3 \\
\hline $26-30$ & 18 & 30.0 \\
\hline $31-35$ & 16 & 26.7 \\
\hline \multicolumn{3}{|l|}{ Occupation } \\
\hline Housewife & 49 & 81.7 \\
\hline Self- employed & 8 & 13.3 \\
\hline Private Employee & 1 & 01.7 \\
\hline Government employee & 2 & 03.3 \\
\hline \multicolumn{3}{|l|}{ Place of residence } \\
\hline Urban & 52 & 86.7 \\
\hline Rural & 8 & 13.3 \\
\hline \multicolumn{3}{|l|}{ Family monthly income } \\
\hline Rs.5,000 - 10,000 & 32 & 53.3 \\
\hline Rs.10,000-20,000 & 22 & 36.7 \\
\hline > Rs. 20000 & 6 & 10.0 \\
\hline \multicolumn{3}{|l|}{ Place of residence } \\
\hline Hindu & 45 & 75.0 \\
\hline Christian & 11 & 18.3 \\
\hline Muslim & 4 & 06.7 \\
\hline \multicolumn{3}{|l|}{ Education Status } \\
\hline PUC level & 20 & 33.3 \\
\hline Primary level & 16 & 26.7 \\
\hline Secondary level & 8 & 13.3 \\
\hline Graduate level & 10 & 16.7 \\
\hline Post graduate level & 6 & 10.0 \\
\hline
\end{tabular}

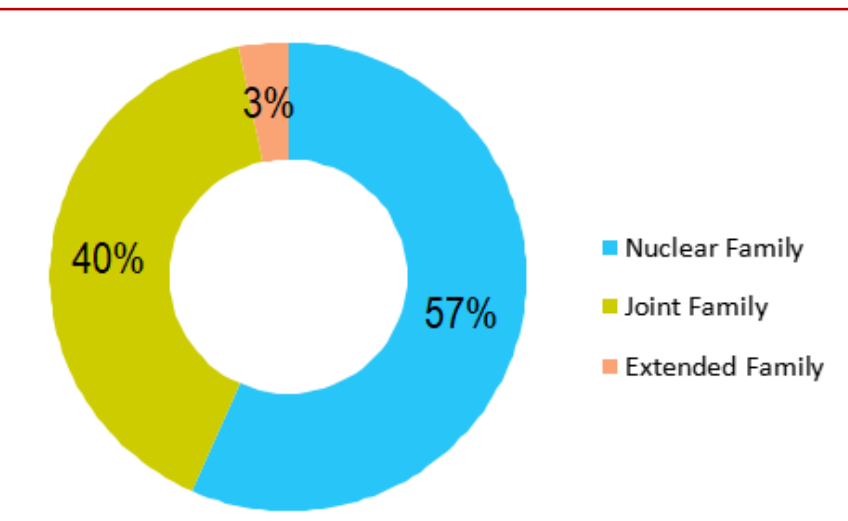

Figure 2I Distribution of antenatal women by type of family 
Overall pre-test and post-test knowledge score of antenatal women $(\mathrm{N}=60)$

In pretest majority of antenatal women 57 (95\%) were having inadequate knowledge and some of them $3(5 \%)$ had moderate knowledge regarding prevention of SBS. However, following the video assisted teaching program, majority of antenatal women $47(78.3 \%)$ had moderate knowledge, 4

\begin{tabular}{|c|c|c|c|c|c|}
\hline \multirow{2}{*}{$\begin{array}{l}\text { Level of } \\
\text { Knowledge }\end{array}$} & \multirow[t]{2}{*}{ Category } & \multicolumn{2}{|c|}{ Pre-test } & \multicolumn{2}{|c|}{ Post-test } \\
\hline & & $\mathbf{N}$ & $\%$ & $\mathrm{~N}$ & $\%$ \\
\hline Inadequate & $\leq 50 \%$ Score & 57 & 95 & 4 & 6.7 \\
\hline Moderate & $51-75 \%$ Score & 3 & 5 & 47 & 78.3 \\
\hline Adequate & $>75 \%$ Score & 0 & 0 & 9 & 15.0 \\
\hline
\end{tabular}

(6.7\%) had inadequate knowledge and 9 (15\%) had adequate knowledge (Table 2).

The ' $t$ ' value computed between mean pre-test and post-test of knowledge score is statistically significant $(\mathrm{p}<0.001)$. Results showed that the mean post-test knowledge score of women regarding prevention of SBS was significantly higher than the pre-test knowledge score (Table 3).

\begin{tabular}{|c|c|c|c|c|}
\hline $\begin{array}{l}\text { Knowledge } \\
\text { Score }\end{array}$ & Mean & SD & 't'-value & p-value \\
\hline Pre test & 11.06 & 2.68 & 25 & $<0.001$ \\
\hline Post test & 19.98 & 1.19 & & \\
\hline \multicolumn{5}{|c|}{ Remarks: Significant } \\
\hline
\end{tabular}

\begin{tabular}{|c|c|c|c|c|c|}
\hline \multirow{2}{*}{$\begin{array}{l}\text { Characteristics } \\
\text { Age }\end{array}$} & \multirow{2}{*}{$\begin{array}{l}\text { Category } \\
21-25\end{array}$} & \multicolumn{2}{|c|}{ Knowledge level } & \multirow{2}{*}{$\frac{x \mathbf{2}}{3.08}$} & \multirow{2}{*}{$\begin{array}{r}\text { Inference } \\
\mathrm{NS}\end{array}$} \\
\hline & & 11 & 15 & & \\
\hline & $26-30$ & 7 & 11 & & \\
\hline & $31-35$ & 10 & 6 & & \\
\hline \multirow[t]{2}{*}{ Religion } & Hindu & 29 & 16 & 4.43 & $S^{*}$ \\
\hline & Christian & 5 & 10 & & \\
\hline \multirow[t]{2}{*}{ Education } & Above Secondary & 8 & 16 & 5.38 & $S^{*}$ \\
\hline & Below Secondary & 23 & 13 & & \\
\hline \multirow[t]{2}{*}{ Occupation } & Housewife & 22 & 27 & 0.335 & NS \\
\hline & Employed & 6 & 5 & & \\
\hline Place of & Rural & 33 & 19 & 2.78 & NS \\
\hline Residence & Urban & 2 & 6 & & \\
\hline Monthly & Rs. 5000-10000 & 13 & 19 & 3.956 & NS \\
\hline Income (in & Rs. $10000-20000$ & 13 & 9 & & \\
\hline Indian Rupees) & More than Rs. 20000 & 1 & 5 & & \\
\hline \multirow[t]{2}{*}{ Gravida } & Primigravida & 14 & 21 & 6 & $\mathrm{~S}^{*}$ \\
\hline & Multigravida & 18 & 7 & & \\
\hline \multirow[t]{2}{*}{ Type of Family } & Nuclear Family & 26 & 8 & 14.6 & $S^{*}$ \\
\hline & Joint family & 7 & 19 & & \\
\hline \multirow{2}{*}{$\begin{array}{l}\text { Previous } \\
\text { Knowledge }\end{array}$} & Yes & 4 & 1 & 4.15 & $S^{*}$ \\
\hline & No & 14 & 41 & & \\
\hline
\end{tabular}

*At 0.05 level of significance, ${ }^{*}=$ significant, $\mathrm{S}=$ Not Significant

Association between pretest knowledge score demographic variables.

There is association between knowledge score and selected sociodemographic variables like religion, education, gravida, types of family and previous knowledge about prevention of Shaken Baby Syndrome (SBS), but there is no association between knowledge score and selected sociodemographic variables like age, occupation, place of residence and monthly income. 


\section{DISCUSSION}

This study reveals that majority of the subjects 26 $(43.3 \%)$ were between the age of $21-25$ years $(43.3 \%)$ and had PUC level qualification (33. 3\%). Majority of antenatal women (58.3\%) subjects were primigravida and $25(41.7 \%)$ were multigravida, and $34(56.67 \%)$ subjects belonged to nuclear family. Most of the subjects 55 (91.67\%) were not having knowledge regarding SBS while $5(8.33 \%)$ had knowledge regarding SBS. A similar type of study, reported maximum $31.66 \%$ education of father and mother upto high school, $56.66 \%$ belonged from joint family, $48.33 \%$ of fathers had private job and $73.33 \%$ of mothers were home worker, $53.33 \%$ had income under less than Rs. 5000/month, $61.66 \%$ had no knowledge about risk of SBS, and $70 \%$ had source of knowledge on SBS through mass media (television) [7].

In pretest, majority of women 57 (95\%) had poor knowledge and some of them $3(5 \%)$ had good knowledge regarding prevention of SBS. However, following the video assisted teaching program majority of antenatal women $47(78.3 \%)$ had moderate knowledge, $4(6.7 \%)$ had inadequate knowledge and 9 (15\%) had adequate knowledge. It was found that the antenatal women had adequate knowledge regarding prevention of shaken baby syndrome after exposed to video assisted teaching program. Similar results were found in study conducted by Pooja Rautela on effectiveness of video assisted teaching on knowledge regarding SBS among caregivers of infants in Pediatric ward at Shri Mahant Indiresh Hospital, Patel Nagar, Dehradun, where in the pre-test $88.33 \%$ sample score $<50 \%$ had inadequate knowledge and $11.67 \%$ had score between $51-75 \%$ had moderate knowledge, which shows majority of sample had inadequate level of knowledge.

In the post-test $80 \%$ sample score ranging between $76-100 \%$ had adequate knowledge, $20 \%$ with score between $51-75 \%$ had moderate knowledge and $0 \%$ of sample score $<50 \%$ had inadequate knowledge. Thus it clearly indicates that there was increase the level of knowledge after video assisted teaching program [8]. In another study conducted in India,

\section{CONCLUSIONS}

The findings of the study revealed that post-test knowledge score was higher than pretest knowledge score regarding prevention of Shaken out of 60 subjects, overall knowledge score during pretest was average in $34(63 \%)$ parents, followed by $23(38 \%)$ poor and $3(5 \%)$ good. The mean for total knowledge score of the parents during pretest was $11.7 \pm 3.46$ which was $40.80 \%$ of total score. The assessment of overall knowledge score during posttest was average in $53(88 \%)$ of parents, followed by $7(12 \%)$ and $0(0 \%)$ poor [7], which is almost parallel to our study. The overall mean pretest score (11.06) and post-test score (19.98) were highly significant $\mathrm{t}(0.05,59 \mathrm{df}=8.92)$.

Also, the mean total knowledge score of the parents during posttest was $19.2 \pm 1.38$ which is $73.63 \%$ of total score in other study is in agreement with our study [7]. It was found that the mean post-test knowledge score of antenatal women regarding SBS was higher than pretest knowledge score. The $t 59$ value was found to be significant at 0.05 level of significance. The mean post-test knowledge score of antenatal women regarding prevention of SBS was significantly higher than the pretest. There was association between knowledge score and selected sociodemographic variables in religion, education, gravida, types of family and previous knowledge about SBS, however there was no association between knowledge score and selected sociodemographic variables like age, occupation, place of residence and income. Similarly, a study conducted by Shindey and Pandey in 2020 showed that, there was no significant association between pretest knowledge score and demographic variables like age of parents and children, gender, religion, father and mother occupation, family income [7]. Similarly, a study conducted by Pooja Rautela in 2018, revealed that there was significant association between the pretest and selected demographic variables like religion and type of family of caregivers of infants with the level of knowledge regarding SBS by using chi square test.

The study also showed that there was no significant association between pretest score of the caregivers relation to the age, educational status, occupation, family income and their source of information [8].

Baby Syndrome among antenatal women. The study concluded that, the video assisted teaching program was an effective teaching strategy, to 
enhance knowledge of antenatal women for prevention of shaken baby syndrome.

\section{ADDITIONAL INFORMATION AND DECLARATIONS}

Acknowledgements: Authors are thankful to Department of Obstetrics and Gynaecological Nursing, Principal, Hospital director of Vydehi Institute of Nursing Sciences \& Research Centre, Bangalore for all their cordial support and co-operation during this study.

Funding: Self

Competing Interests: There is no conflict of interest regarding the publication of this article.
Author Contributions: PY contributes to the design of the study, analysis and write up of the manuscript. All authors contributed to data analysis, drafting or revising the article, gave final approval of the version to be published, and agree to be accountable for all aspects of the work.

Data Availability: Data will be available upon request to corresponding authors after valid reason

\section{REFERENCES}

1. Christian CW, Block R. Abusive Head Trauma in Infant and Children. Pediatrics. 2009; 123(5):1409-11.

2. Dias MS, Smith $K$, De Guehery K, Mazur P, Li V, Shaffer ML. Preventing abusive head trauma among infants and young children: A hospitalbased, parent education program. Pediatrics. 2005; 115(4):470-77.

3. Hoyle, Brian. "Shaken Baby Syndrome." Gale Encyclopedia of Neurological Disorders. 2005. Encyclopedia.com.

4. Caffey J. On the theory and practice of shaking infants: its potential residual effects of permanent brain damage and mental retardation. American journal of disease of children. 1972; 124:161-69.
5. Matschke J, Herrmann B, Sperhake J, Korber F, Bajanowski T. Shaken Baby Syndrome A Common Variant of Non-Accidental Head Injury in Infants.DeutschesArzteblatt International. 2009; 106(13):21117.

6. Goulet C, Fortin S, Déziel L. Development and Evaluation of a Shaken Baby Syndrome Prevention Program. Journal of Obstetrics and Gynecol. 2009;38:7-21.

7. Shindey U, Pandey E. preexperimental study to evaluate the effectiveness of video assisted teaching programme on knowledge regarding shaken baby syndrome amongparents of infants and toddlers. Universe International Journal of Interdisciplinary Res. 2020;1(7):75-79.
8. Pooja R. Effectiveness of Video Assisted Teaching on Knowledge regarding Shaken Baby Syndrome (SBS) among Caregivers of Infants in Pediatric Ward at Shri Mahant Indiresh Hospital, Patel Nagar, Dehradun. International Journal of Science and Res. 2020; 9(8):856-59. 